\title{
Word of Mouth in Hospitality Management: The Case of Luxury Hotels in China
}

\author{
María José Álvarez Gil and Wei Yan \\ Departmento de Economía de la Empresa \\ Universidad Carlos III de Madrid \\ \{maria.alvarez, wei.yan\} @uc3m.es
}

\begin{abstract}
As the most important emerging market and the second biggest luxury goods consumer, China has been receiving a growing amount of foreign investment in luxury hotels. This paper studies China's luxury hotel industry in terms of its customers' word-of-mouth (WOM) on hotel staying experiences in five-star hotels of Western and Chinese origins in Beijing and Shanghai. Analyses on the WOM are made from three perspectives: online booking site vs. online meta-search site; Western and Hong Kong/ Macau/ Taiwan/ Singapore (HMTS) hotels vs. Chinese hotels; and hotels in Beijing vs. hotels in Shanghai. These three perspectives respectively draw on the incentive, cultural, and geopolitical factors in evaluating luxury hotels in China. Results of this study are useful for companies in the hospitality industry operating in emerging markets by providing the most updated insights from the most vivid case of the emerging economies.
\end{abstract}

Keywords: internationalization, China, luxury hotels, word-of-mouth.

\section{Introduction}

Luxury goods include both luxury products and services. This original study deals with an important type of luxury service-luxury hotels-by assessing the word-ofmouth (WOM) among customers. The paper uses the case of the most important and fast-growing emerging market-China, to analyze luxury hotel staying experiences. This is a market of growing importance, as nowadays virtually all Western hotel chains and brands have entered China and are facing fierce competition from local hotels. How to adapt their service and products to local customers, and how would local customers rate the staying experience compared with local hotels, are key issues to understand in the process of Western hotels' internationalization.

In this study, analyses were done from various perspectives using online reviews of hotel guests, and the online reviews have been analyzed based on three groups of comparisons: Western and Hong Kong/ Macau/ Taiwan/ Singapore (HMTS) hotels vs. Chinese hotels; hotels in Beijing vs. hotels in Shanghai; and most notably, online booking site vs. online meta-search site, which are the two major types of websites people use to get informed and make reservations for travels. Important issues such as information asymmetry, incentive level, cultural and geopolitical influences are 
discussed. It is concluded that online booking sites tend to report better customer reviews compared with meta-search sites, and according to customers' reviews, Chinese luxury hotels somewhat underperform their foreign counterparts operating in China. Implications of this study provide valuable insights and recommendations for luxury hotels operating in China and other emerging markets.

The rest of the paper is organized as follows. Part 2 and 3 give the background knowledge of the luxury hotel industry in China and the WOM used to evaluate the hotels' service. Part 4 reviews the literature and proposes the hypotheses. Part 5 and 6 draw on the data and methodology used in this study as well as the main results. Conclusion, recommendations, limitations and areas for further research are provided in part 7.

\section{Growth of Hotel Industry in China}

The development of the hospitality industry in China has been dramatic since the last two decades. According to China National Tourism Administration (CNTA), the hotel industry of China has been growing rapidly from only 137 star-rated hotels in early 1980 s to 14,237 in 2009 . In 2010 , the country received 55.7 million international tourists, ranking third in the world (after United States and France), which generated $\$ 45.8$ billion USD income, ranking it fourth in the world (CNTA). The domestic tourism market of China is even larger; it is estimated to be at least 10 times larger than the international inbound tourism (CNTA).

On the other hand, Internet using in China is also growing at a rapid rate. China already has the greatest number of "netizens" in the world. According to Internet World Stats, as of December 2010, China has 460 million Internet users, which represents $23 \%$ of the whole world's Internet users. Along with the increasing number of both hotel and Internet users, the way that people reserve or purchase travel services and products is undergoing profound changes. The growing importance of the Internet as an electronic medium has led to the emergence of various forms of online travel distribution channels (Law et al. 2007). The rapid growth of Internet applications on the hospitality industry in turn leads to an enormous and ever-growing amount of consumer-generated online reviews on travel products and services. According to Gretzel and Yoo (2008), more than three-quarters of travelers have considered online consumer reviews as an important information source when planning their trips.

\section{Word-of-Mouth (WOM)}

Word-of-mouth (WOM) refers to the interpersonal communications among consumers concerning their personal experiences and evaluations of a product or a brand (Richins, 1983). While electronic word-of-mouth (eWOM) refers to those same interpersonal communications but taken place via an electronic platform, usually via the Internet. Since WOM is a consumer-made channel of information communications where the author of the evaluation is independent of the product or service provider, it is therefore perceived to be more credible and reliable by consumers than firm-generated information 
(Schiffman \& Kanuk, 1995). Moreover, through multiple exchanges among consumers, a single WOM message can reach and potentially influence a huge number of consumers (Lau \& Ng, 2001).

The influence of eWOM can be directly applied to the hospitality industry as online user-generated reviews have become an important source of information for travelers. Since consumers may not fully know about a hotel before consumption, they might seek WOM information from an experienced and trusted source. Therefore, the eWOM offers consumers an efficient solution to the "intangibility" of such products (Klein, 1998). Moreover, as Gretzel and Yoo (2008) stated, online travel reviews are often perceived as more likely to provide up-to-date and reliable information than reviews posted by travel service suppliers. And since negative consumer opinions can substantially influence customers' perception of a company's image, online WOM exchange platforms may be used by consumers as an important instrument of power.

\section{$4 \quad$ Hypotheses Proposing}

Due to the perishable nature, hospitality products are particularly suitable for online distribution channels (Rong et al., 2009). Among all online channels, there are two major types of online travel sites: online travel-booking sites, and online travel metasearch sites. Online travel-booking sites are traditional online travel intermediaries that sell hotel rooms from a number of different hotels to offer a full range of products and services to potential hotel guests. Examples of online travel-booking sites include Expedia, Travelocity, Orbitz, Pricelines, ctrip, etc. Travel meta-search engines differ from traditional online booking sites in that they do not directly process booking transactions. Instead, they link consumers to the travel supplier where the actual booking transaction will take place. The meta-search sites are then compensated for the role they play in the booking process. Examples of travel meta-search sites include Kayak, Side Step, daodao, etc.

Based on the different transaction schemes of the two types of websites, the issue of independence and incentives of the information provider can be discussed. Incentive misalignments can arise from the inverse relationship between rewards and the quality of the report from the information provider: Travel-booking sites, which earn commission from the intermediary role they play in the transaction, may have incentives to cheat on the ratings; while meta-search sites, which do not earn compensation through guests' bookings, may not have incentives to do so.

Hypothesis 1: Online travel-booking websites are reporting better customers' WOM on luxury hotels than meta-search websites.

Chinese hotels, many of them state-owned ones, are growing at a rapid rate especially since the past two decades. With the ongoing economic reforms, Chinese hotels have been gradually transformed from government-orientated to market-orientated. However, gaps still exist when compared with their international competitors. Externally, Chinese hotels are generally considered to be hindered from multiform ownership, fierce competition, and a sophisticated legal system. Internally, Chinese hotels often lack skillful personnel and the know-how. 
On the other hand, international hotel groups are developing upscale and luxury hotels in forms of wholly owning, joint ventures, or management contracts to take advantage of the enormous business opportunities in China (Pine, 2002). Despite the barriers preventing international hotels' development, which can be foreign currency control, local government interference, and in particular, lack of personal relationships and networking known as "guanxi" (Heung et al., 2008), international luxury hotels tend to have more competitive advantages resulted from economy of scale, brand prestige, management expertise and IT platforms. Indeed, as found by Pine and Phillips (2005), international hotels in China have achieved higher occupancy, profit, and brand awareness compared with their Chinese counterparts.

Hypothesis 2: Western and Hong Kong/ Macau/ Taiwan/ Singapore luxury hotels are receiving better WOM than Chinese luxury hotels.

Another perspective of the research is the geopolitical differences of the cities in which hotels are located. The two most important Chinese cities-Beijing and Shanghai-are compared here. The two cities are overall quite similar in terms of dimension, population, level of development, as well as hospitality products and services provided. However, differences exist in their function, orientation, and level of control. Beijing, the Chinese capital, is the political and cultural center of the country. On one hand, it enjoys the most direct governmental and political preferences and advantages. On the other hand, it is also more directly controlled by the central government. Shanghai, the economic and financial center of China, has somewhat less direct governmental control compared with the capital.

An important constraint of state-owned hotels, which are more common in Beijing, is the non-commercial objectives which somehow prevent their reform and affect their competitiveness. Moreover, business objectives are often unclear in state-owned hotels of China (Heung et al., 2008), as the development of luxury hotels is often related to the status and aspirations of local entrepreneurs and politicians, with somewhat less concerns over the real market needs (Dai, 2006).

Hypothesis 3: Luxury hotels in Shanghai are receiving better WOM than luxury hotels in Beijing.

\section{Data and Methodology}

For this study, Beijing and Shanghai are chosen because they are the most important Chinese cities receiving most visits from either domestic or international, business or leisure travelers. Moreover, these two cities represent the latest and most vivid image of modern China and are therefore, updated with the latest trend and standard of hospitality products and services. Two Chinese travel websites are chosen for this study: ctrip.com, the country's most important travel-booking site with over 40 million members and a network of over 32,000 hotels worldwide, and daodao.com, one of the most popular meta-search sites among the Chinese, with more than 20 million members and over 40 million online ratings by real travelers. Both websites are nationwide considered as most popular and reliable sites. These sites are often identified as opinion leaders and help accelerate the information diffusion. 
In total, data from 202 five-star hotels in Beijing and Shanghai (of which 109 in Beijing and 93 in Shanghai) are used, and hotels used on both websites are exactly the same ones. All ratings are on a scale of 1 to 5. Rating providers are predominantly Chinese. The ratings were manually collected during July and August of 2011. A demographic summary is provided in Table 1.

Table 1. Sample demographics

\begin{tabular}{|l|l|l|l|}
\hline City & Origin & N & Percentage \\
\hline Beijing & Chinese & 63 & $57.8 \%$ \\
\hline & Western & 35 & $32.1 \%$ \\
\hline & HMTS & 11 & $10.1 \%$ \\
\hline & Subtotal & 109 & $100 \%$ \\
\hline Shanghai & Chinese & 32 & $34.4 \%$ \\
\hline & Western & 53 & $57.0 \%$ \\
\hline & HMTS & 8 & $8.6 \%$ \\
\hline Combined & Subtotal & 93 & $100 \%$ \\
\hline & Chinese & 95 & $47.0 \%$ \\
\hline & Western & 88 & $43.6 \%$ \\
\hline & HMTS & 19 & $9.4 \%$ \\
\hline & Total & 202 & $100 \%$ \\
\hline
\end{tabular}

To compare the ratings between websites, cities, and types of hotels, mean difference and two-sample t-test were conducted. As presented in the following tables, the types of hotels are classified into Chinese, Western, and HMTS (Hong Kong/ Macau/ Taiwan/ Singapore). Note here that non-Chinese hotels are divided into two groups: Western and HMTS, that is because HMTS hotels are culturally Chinese though they are closer to Western style when it comes to managerial issues. By dividing them into a separate group, more insights are expected to be provided.

Apart from the overall ratings used to test the hypotheses, categorized ratings (e.g., service, location, cleanliness) were also obtained from the websites. The average value for Chinese and Western luxury hotels in Beijing, Shanghai, and both cities were obtained. These rating, as the overall ratings, are also in the 1 to 5 Likert scale. Results of the categorized ratings are expected to help Chinese and Western luxury hotels to gain better knowledge of their strengths and weaknesses.

\section{$6 \quad$ Results}

To test Hypothesis 1, comparisons in terms of rating differences between ctrip.com and daodao.com (ctrip ratings minus daodao ratings) were done on each type of the hotels plus the combined types. As Table 2 demonstrates, results are surprisingly similar among the four groups. That is to say, ctrip provides significantly better ratings than daodao for luxury hotels in Beijing and Shanghai regardless of the origin of the hotels. These results give evidence to what has been argued previously on the incentive issue and thus supports Hypothesis 1. 
Table 2. Mean Difference (t-test) between websites (ctrip - daodao)

\begin{tabular}{|c|c|c|c|c|}
\hline & Chinese & Western & HMTS & combined \\
\hline $\begin{array}{l}\mathrm{BJ} \\
+\mathrm{SH}\end{array}$ & $\begin{array}{r}.2494737 \\
(6.2157 * * *)\end{array}$ & $\begin{array}{l}.2772727 \\
(8.3055 * * *)\end{array}$ & $\begin{array}{l}.2263158 \\
(2.8939 * *)\end{array}$ & $\begin{array}{l}.2594059 \\
(9.8734 * * *)\end{array}$ \\
\hline BJ & $\begin{array}{r}.2380953 \\
(4.5979 * * *)\end{array}$ & $\begin{array}{l}.2599999 \\
(4.6856 * * *)\end{array}$ & $\begin{array}{l}.2272727 \\
\left(2.6236^{* *}\right)\end{array}$ & $\begin{array}{l}.2440367 \\
(6.1907 * * *)\end{array}$ \\
\hline SH & $\begin{array}{c}.271875 \\
\left(4.4526^{* * *}\right)\end{array}$ & $\begin{array}{l}.2886792 \\
(7.0545 * * *)\end{array}$ & $\begin{array}{l}.2250001 \\
(1.6550 *)\end{array}$ & $\begin{array}{l}.2774193 \\
\left(8.2535^{* * *}\right)\end{array}$ \\
\hline
\end{tabular}

For Hypothesis 2, analyses were done on both websites, and mean difference and two-sample t-test were obtained. As can be seen in Table 3, hotels in Beijing and hotels in Shanghai were treated separately and combined. Comparing Chinese hotels and Western hotels, negative mean differences were obtained, and the t-test demonstrates that all those differences are significant. Similar results were obtained when comparing Chinese hotels and HMTS hotels. For the comparison between Western and HMTS hotels, no significant results were obtained. For DaoDao (Table 4), similar results were obtained. Thus Hypothesis 2 is supported.

Table 3. Mean difference (t-test) among hotels types (ctrip)

\begin{tabular}{|c|l|l|l|}
\hline Ctrip & Chinese - Western & Chinese - HMTS & Western - HMTS \\
\hline BJ & -.1764115 & -.1957895 & -.019378 \\
+ SH & $(-4.3165 * * *)$ & $(-2.5539 * *)$ & $(-0.3226)$ \\
\hline BJ & -.2425397 & -.2916306 & -.0490909 \\
& $(-3.8859 * * *)$ & $(-2.8460 * *)$ & $(-0.6420)$ \\
\hline SH & -.0949882 & -.046875 & .0481132 \\
& $(-1.7018 *)$ & $(-0.4172)$ & $(0.5157)$ \\
\hline
\end{tabular}

Table 4. Mean difference (t-test) among hotels types (daodao)

\begin{tabular}{|c|l|l|l|}
\hline daodao & Chinese - Western & Chinese - HMTS & Western - HMTS \\
\hline BJ & -.1486125 & -.2189474 & -.0703349 \\
+ SH & $(-4.4779 * * *)$ & $(-3.7472 * * *)$ & $(-1.3137 *)$ \\
\hline BJ & -.220635 & -.3024531 & -.0818181 \\
& $(-4.2863 * * *)$ & $(-3.8233 * * *)$ & $(-1.0272)$ \\
\hline SH & -.078184 & -.0937499 & -.015566 \\
& $(-1.7915 *)$ & $(-1.1335)$ & $(-0.2186)$ \\
\hline
\end{tabular}

Finally, to compare hotels in Beijing and hotels in Shanghai for Hypothesis 3, similar analyses were conducted. As Table 5 shows, comparisons based on different websites as well as different types of hotels were done. Results in this table are the differences between Beijing and Shanghai in each of the hotel types and websites. For 
ctrip.com, no statistically significant results were found, and for daodao.com, the only significant result is that Western and HMTS hotels are slightly doing better in Beijing than in Shanghai. But overall, no significant results were obtained. Therefore, Hypothesis 3 cannot be supported.

Table 5. Mean difference (t-test) between cities (Beijing-Shanghai)

\begin{tabular}{|l|l|l|}
\hline & ctrip.com & daodao.com \\
\hline Chinese & $-.0856647(-1.2685)$ & $-.0518849(-1.0135)$ \\
\hline Western & $.0618868(1.2321)$ & $.0905661(2.0032 *)$ \\
\hline HMTS & $.1590909(1.3169)$ & $.1568182(1.6498 *)$ \\
\hline Combined & $-.0365197(-0.8968)$ & $-.003137(-0.0934)$ \\
\hline
\end{tabular}

In terms of the categorized ratings, as can be seen in Table 6, among all the six categories included in the study. Western hotels have obtained better results than their Chinese counterparts in both cities. However, rating difference exists among the six categories with Cleanliness rated highest and Value rated lowest. This difference, especially the lowly rated Value, deserves additional attention, as it implies that consumers would pay less for the service and product they got or, demand something more for the money they paid.

Table 6. Categorized ratings (average value)

\begin{tabular}{|l|l|l|l|l|l|l|}
\hline Western & Cleanliness & Service & Location & Facilities & Comfort & Value \\
\hline Beijing & 4.67 & 4.40 & 4.35 & 4.45 & 4.26 & 3.90 \\
\hline Shanghai & 4.63 & 4.27 & 4.30 & 4.38 & 4.19 & 3.84 \\
\hline BJ+SH & 4.64 & 4.32 & 4.32 & 4.41 & 4.22 & 3.86 \\
\hline
\end{tabular}

\begin{tabular}{|l|l|l|l|l|l|l|}
\hline Chinese & Cleanliness & Service & Location & Facilities & Comfort & Value \\
\hline Beijing & 4.44 & 4.10 & 4.21 & 4.13 & 4.02 & 3.85 \\
\hline Shanghai & 4.54 & 4.14 & 4.23 & 4.28 & 4.11 & 3.84 \\
\hline BJ+SH & 4.48 & 4.11 & 4.22 & 4.18 & 4.05 & 3.85 \\
\hline
\end{tabular}

\section{Conclusion and Recommendations}

This study draws on the issue of WOM differences in terms of reservation website, hotel origin, and location. It has been found that the traditional online booking site (ctrip.com) in China provides significantly better WOM than the novel meta-search site (daodao.com), and that, overall, Chinese luxury hotels underperform their Western and HMTS counterparts in China, giving space for further improvements and reforms towards a more customer-oriented business model. As to location difference, no significant WOM difference was found between Beijing and Shanghai, which implies that difference in political and functional orientations does not necessarily lead to difference in service providing in hospitality industry.

There are several novelties and contributions of this study. The two types of the above mentioned travel websites are studied in conjunction, which is few, if not none, 
in the literature. And studies of this combination were especially scarce for emerging markets. Moreover, cultural factors in this study are drawn from the opposite direction of the majority of the literature where cultural diversity lies in service receivers, while here the cultural diversity arises from service providers. Finally, managerial implications and recommendations for luxury hotels of China are provided, which is a valuable knowledge asset for strategic and operational improvements for both Chinese and non-Chinese players in this sector.

As to limitations and further research, since WOM behavior is likely to change over the customer life cycle, long-term effects of WOM communication and effects on the Internet can be studied using longitudinal data. Meanwhile, similar studies on other sectors of the tourism industry such as airlines and catering sectors can be carried out. Furthermore, the scope of this study can be extended beyond China by studying and comparing cases in other emerging markets.

\section{References}

1. CNTA (China National Tourism Administration), http: / / www . cnta. com

2. Dai, B.: China's State-owned Hotels: The Development Course of Strategic Adjustment. In: Chinese Tourism Research Annual 2005 Tourism Tribune. Social Sciences Academic Press, Beijing (2006)

3. Gretzel, U., Yoo, K.: Use and impact of online travel reviews. In: Information and Communication Technologies in Tourism 2008, pp. 35-46. Springer (2008)

4. Heung, V., Zhang, H., Jiang, C.: International franchising: Opportunities for China's stateowned hotels? International Journal of Hospitality Management 27, 368-380 (2008)

5. Internet World Stats, http://www. internetworldstats.com

6. Klein, L.R.: Evaluating the potential of interactive media through a new lens: search versus experience goods. Journal of Business Research 41, 195-203 (1998)

7. Lau, G.T., Ng, S.: Individual and Situational Factors Influencing Negative Word-of-Mouth Behavior. Canadian Journal of Administrative Sciences 18, 63-178 (2001)

8. Law, R., Chan, I., Goh, C.: Where to find the lowest hotel room rates on the internet? The case of Hong Kong. International Journal of Contemporary Hospitality Management 19(6), 495-506 (2007)

9. Pine, R.: China's hotel industry: serving a massive market. The Cornell Hotel and Restaurant Administration Quarterly 43(3), 61-70 (2002)

10. Pine, R., Phillips, P.: Performance comparisons of hotels in China. International Journal of Hospitality Management 24, 57-73 (2005)

11. Richins, M.L.: Negative word-of-mouth by dissatisfied consumers: a pilot study. Journal of Marketing 47(1), 68-78 (1983)

12. Rong, J., Li, G., Law, R.: A contrast analysis of online hotel web service purchasers and browsers. International Journal of Hospitality Management 28, 466-478 (2009)

13. Schiffman, L.G., Kanuk, L.L.: Consumer Behavior, 9th edn. Prentice Hall, Upper Saddle River (1995) 